\title{
KATSE KIRJELDADA ARTEFAKTINIMESID
}

\author{
Tiina Laansalu, Peeter Päll ja Tõnu Tender \\ Eesti Keele Instituut
}

\begin{abstract}
Kokkuvõte. Artefaktinimed on traditsiooniliselt liigitatud kultuurnimede alaliigiks, mis hõlmab inimese loodud rajatiste nimesid. Inimtekkeliste objektide hulk on tänapäeval aga üha suurem ja erinäolisem, eriti linlikus keskkonnas, mistõttu vajab traditsioonilise kohanimede klassifikatsiooni artefaktinimede rühma kirjeldus täpsustamist ja täiendamist. Artikkel vaatleb artefaktinimesid kolmes kasutussfääris: maapiirkonnas, linnapiirkonnas ja slängis. Ruraalsete artefaktinimede puhul on analüüsitud Harjumaa Jüri ja Kose kihelkonna kohanimistuid, urbonüümide alusandmed pärinevad KNABist ning keskenduvad suures osas Tallinna nimedele. Slänginimede puhul on esitatud valdavalt Tallinna ja Tartu näited, mis pärinevad eri aegadel valminud teadustöödest, artiklitest ning internetist.
\end{abstract}

Märksõnad: onomastika, kohanimed, artefaktinimed, linnakohanimed, slänginimed, eesti keel

DOI: https://doi.org/10.12697/jeful.2020.11.1.07

\section{Sissejuhatus}

Sõna artefakt pärineb ladina keelest (ld arte 'kunstlikult' + factum 'tehtud'). Terminiga artefaktinimi on onomastikas tähistatud kohanimesid, mis märgivad teatud inimtekkelisi objekte. Artefaktinimed on seni eraldi käsitlemist leidnud võrdlemisi vähe. Siinse artikli eesmärk on selgitada, mis täpsemalt on artefaktinimi ja mis liiki nimeobjekte võib mõiste hõlmata nii traditsioonilises maapiirkonnas kui ka uudses linnakeskkonnas, ning ühtlasi käsitleda mõningaid artefaktinimede klassifitseerimisel ilmnevaid kitsaskohti ja ebaselgusi. Eraldi tuuakse esile artefaktide nimed slängis, mis võivad käia nii maa- kui ka linnapiirkonna kohta, sest see väärib oma spetsiifika tõttu eraldi tähelepanu.

Alustuseks on paslik vaadata, mida ütlevad sõna artefakt kohta nüüdisaja sõnaraamatud. Eesti Keele Instituudi uusimas sõnastikuportaalis Sõnaveeb ilmunud „Eesti keele sõnaraamatus“ (EKS 2019) 
on artefakti seletus järgmine: ,(hrl arheoloogias, kultuuriuuringutes:) inimese tehtud või ümberkujundatud ese, nt tööriist, kunstiteos". ÕS 2018 märksõna artefakt ei esita, samuti ei leidu sõna 2009. aastal ilmunud „Eesti keele seletavas sõnaraamatus“. Põhjaliku sõnaseletuse annab „Võõrsõnade leksikon“ (2012): ,inimese poolt teadlikult kindlaks otstarbeks olemasolevast materjalist valmistatud ese; ürgaegne kivi- $\mathrm{v}$ luuriist; BIOL mõnikord organismi uurimisel tekitatav moodustis $\mathrm{v}$ protsess, mis pole hrl organismile omane“. Terminit artefaktinimi nimetatud sõnaraamatutest ei leia. Väljatoodud seletuste põhjal võime järeldada, et sõna artefakt kasutatakse üldkeeles inimese loodud asjadele-esemetele viidates. See tähendusväli on mõnevõrra kitsam kui onomastikas tarvitatud mõistes artefaktinimi, mis on hõlmanud tavapärastest ,asjadest“" suuremate objektide nimesid.

Mida on onomastikas artefaktinimedeks nimetatud? Traditsiooniline kohanimeliigitus jaotab kohanimed loodusnimedeks ja kultuurnimedeks. Loodusnimed jagunevad omakorda vetenimedeks (nt mere-, jõe- ja järvenimed) ning maastikuobjektide nimedeks (nt mäe-, oru-, metsa- ja neemenimed), kultuurnimed aga asustusnimedeks (nt talu-, küla- ja linnanimed), viljelusnimedeks (nt heinamaa-, karjamaa- ja põllunimed) ning artefaktinimedeks (vt Ainiala et al. 2012: 23-24, Kallasmaa 2005: 136 ja Kiviniemi 1990: 46). ${ }^{1}$ Marja Kallasmaa (2005: 136) sõnul on selline liigitamine tegelikult tinglik, sest eks artefaktidki sõltuvad inimasutusest, kuid ,selle rühma eraldi väljatoomine on ilmselt põhjendatud asjaoluga, et maaga sellel otsene seos puudub. Kui küla ja samuti talu saab ette kujutada mingi territooriumina, siis artefakt ainult toetub maapinnale oma põhjaga. Siia kuuluvad sillad, küünid, väravad ja mõne autori meelest ka kivid, ehkki neid ei ole teinud inimene.“" Jaotuse tinglikkus ilmneb veel näiteks asjaolus, et viljelusobjektidki on inimeste rajatud ning seega otsekui artefaktid, teisalt on need aga tihedalt seotud looduse ja maastikuga. Piiripealseid nimesid saab välja tuua mitmeid, näiteks võib vaielda, kas parginimed on loodus- või kultuurnimed ning kas tiigi- ja kraavinimed on vete- või artefaktinimed. Segane lugu on soonimedegagi, mida kord on liigitatud maastikuobjektide, kord vetenimede hulka (vt ka Faster 2018, 2020). Samuti sobivad kunagised kõrtsi- ja veskinimed üheaegselt nii artefaktinimede

Jaak Simmu artiklis „Nimeteaduse põhimõisteid“ (1976) ja Peeter Pälli ülevaates „Eesti kohanimed“ (2018) ei ole artefaktinimed käsitlemist leidnud. 
kui ka asustusnimede rühma - olid ju kõrtsi- ja veskikohad samasugused asustusüksused nagu muud talukohad.

Lisaks eelnimetatud sildade, küünide ja väravate nimedele on artefaktinimedeks liigitatud veel teenimesid, tamminimesid ,ja teiste ehitiste nimesid“" (vt Ainiala 2002: 298 ja Ainiala et al. 2012: 66). Artefaktinimed paistab olevat nimeliik, mille alla (sõltuvalt konkreetsest käsitlusest) klassifitseeritakse need inimtegevusest sündinud või selle poolt mõjutatud objektide nimed, mis teiste kultuurnimede (asustusnimed, viljelusnimed) alla ei sobitu. Kuhu täpsem piir tõmmatakse, tuleks vajadusel aga iga uurimuse puhul eraldi välja tuua.

\section{Artefaktid maapiirkonnas}

Analüüsimaks, millised artefaktinimed esinevad traditsioonilises maapiirkonna kohanimistus, keskendub siinne peatükk kahe Harjumaa kihelkonna, täpsemalt Jüri ja Kose kihelkonna kohanimedele. ${ }^{2}$ Alusmaterjal pärineb Eesti Keele Instituudi kohanimekartoteegist (KN), mis kujutab endast möödunud sajandi jooksul kogutud klassikalist kohanimekogu, milles on põhirõhk ruraalsel kohanimistul. Jüri ja Kose kohanimesedeleid on kartoteegis kokku 7205 ja need on kogutud järgmiselt: 1920.-30. aastatel 10\% sedelitest, 1950. aastatel tervelt 58\% sedelitest, 1960.-70. aastatel $26 \%$ sedelitest ning 1980.-90. aastatel 6\% sedelitest. Seega peegeldab kohanimekogu nende kihelkondade puhul valdavalt just 1950.-70. aastate kohanimistut. Materjali koondamiseks kasutati kohanimekartoteegi veebiversiooni (KNV).

Käesolevas töös on artefaktinimede hulka arvatud ka mõnel juhul asustusnimedeks liigituvaid kohanimesid. Niisugusteks objektideks on needsamad eelpool mainitud kõrtsid ja veskid, aga ka näiteks koolimajad/koolitalud, mis on lisaks kindla funktsiooniga ehitisele funktsioneerinud ühtlasi kompleksse talumajapidamisena ning mille nimi on toiminud tavapärase asustusnimena. Sageli on neil eksisteerinud ka mitu rööpselt kasutusel olevat nimevarianti, näiteks Nõmme kõrts Nõmmekõrtsu (talu), Oti veski Otiveski (talu). Analüüsis arvessetuleku tingimuseks on, et artefaktinimetus esineb nimes nominatiivse

\footnotetext{
Jüri ja Kose kihelkonna kohanimedest (eeskätt asustusnimedest) saab huviline lähemalt lugeda Tiina Laansalu doktoritööst „Kesk-Harjumaa kohanimede kujunemine ja nimesiire" (2020).
} 
põhisõnana. Asustusnimedes väga sageli esinevad mõisted, nagu maja ja saun on kaasatud ainult siis, kui need on kohanimede põhiosana ehk determinandina liittüve osaks (nt Metsamaja) või esinevad terminnimena (nt Saun) (vrd ka Saar 2008: 69).

Jüri ja Kose kihelkonna kohanimematerjali läbitöötamise tulemusel valmis järgmine determinandina esinevate artefaktinimetuste sagedusloend:

- kü̈̈n (57);

- kõrts (44);

- tee (37);

- veski (18);

- maantee (17);

- kool koolimaja (14);

- tänav (14);

- $\operatorname{sild}(13)$

- $\operatorname{rehi}(9)$

- teomaja(d) (8);

- karjalaut (7);

- kaev (6);

- (bussi)peatus (5);

- tuuleveski (5);

- trumm 'väike sild' (4);

- kolmel korral esinesid: (magasi)ait, bussipaviljon, kabel, katlamaja, kivikalme, mulk 'värav, aiaauk', mõisamaja, ots (teeosanimetus), patarei 'suurtükipatarei', pood, rahvamaja, surnuaed;

- kahel korral: aiand, internaat, (raudtee)jaam, kirik, lakivabrik, meierei, metsavahimaja, moonakate maja, nõiakaev, postimaja, saun, vallamaja, värav;

- ühel korral: allee, baas, barakid, blindaaž, hobusetall, jahimaja, juurviljahoidla, kaalumaja, kanala, kasarm, kelder, kellamaja, klubi, koorejaam, kruusiauk 'kruusaauk', kuivati, kurve 'kurv', kääne 'käänak', laskemoonaladu, laskeplats, lastesõim, lõhkeaineteladu, metsamaja, mälestusmärk, palk (sillanimetus), paviljon, plats, puukuurid, seltsimaja, sidurivabrik, siht, talitee, tallid, tehnikum, tellisetönk 'tellisetöökoda', toru (teeosanimetus), toruvabrik, tsehh, tuulik, tõllahoone, vasikalaut, viinavabrik, õlletehas. 
Koostatud loendist ilmneb, et sagedasimad artefaktinimerühmad vaadeldud piirkonnas on küüninimed (nt Eeskopli kü̈̈n, Loigu küün, Ussisoo kü̈̈n), kõrtsinimed (nt Kabeli kõrts, Kõvera kõrts, Raudalu kõrts), teede ja tänavate nimed (nt Kindluse tee, Pargi tänav, Teomeeste tee, Viljandi maantee), veskinimed (nt Kiili veski, Oti veski, Tuhala veski) ja koolinimed (nt Kaarepere kool, Lehmja kool, Nabala koolimaja). Analüüsitud Põhja-Eesti piirkonna tulemusi võrreldi Lõuna-Eestis tehtud uurimusega - Evar Saare doktoritööga „Võrumaa kohanimede analüüs enamlevinud nimeosade põhjal ja traditsioonilise kogukonna nimesüsteem“ (2008). Võrdlusest Võrumaaga selgus, et kohanimede sagedamatest põhiosana esinenud artefaktinimetustest kattuvad sild, veski, koolimaja, tee (lõunaeesti tii) ja kõrts. Lisaks neile sisaldasid Võrumaa sagedasimad artefaktinimed sõnu mõtsavahikotus 'metsavahikoht', puut 'pood', tsiht 'siht', vallamaja, kerik 'kirik', surnuaid 'surnuaed' ja maja (lähemalt vt Saar 2008: 86-89), mille vasted on kõik leitavad ka Jüri-Kose kohanimistus, kuid mõnevõrra vähem sageda esinemusega. Erandlikult ei esine siinne sagedasim artefaktinimetus kü̈̈n Võrumaa loendis. Põhjusi selleks võib olla kaks: 1) nimed on kogutud eri ajal, Võrumaa näited koguti 2000. aastate algul, mil küünid olid juba kadunud, samas kui Jüri ja Kose nimed koguti aastakümneid varem; 2) kogumisspetsiifika - Võrumaa nimede kogumisel keskenduti enim kaardil hästi silma paistvatele objektidele.

Niisiis järeldub, et sagedasimate traditsiooniliste ruraalsete artefaktide tüübid on olnud piirkonniti samad, mistõttu on samad ka sagedamad artefaktinimetused, olgugi et nimetuste kirjapildis kajastub murdejooni (pood $\sim$ puut, surnuaed $\sim$ surnuaid, tee $\sim$ tii). Analüüsitud maapiirkonna-artefaktinimede struktuur on valdavalt klassikaline ja tavapärast eesti kohanimede malli järgiv (nimetuum + liigisõna). Järgnev peatükk keskendub artefaktidele ja artefaktinimedele linnalikus keskkonnas.

\section{Artefaktid linnapiirkonnas}

Linnamaastikus ehk tiheasustusalal on artefaktid pea kõik, mida liigitada saab, sest linn on tervikuna inimtekkeline nähtus. Vastavalt eespool esitatud kultuurnimede tavapärasele jaotusele (asustusnimed, viljelusnimed, artefaktinimed) jääksid siinsest vaatlusest kõrvale üksnes 
linnaosade ja asumite nimed kui asustusnimed; viljelusnimesid klassikalises mõttes linnades pigem pole. Ent artefaktinimede liigitamise suurim probleem näib siin olevat see, mida üldse kohanimeks saab pidada. Linn kui elukeskkond on kirev ja dünaamiliselt muutuv. ${ }^{3}$

Linnas on kõigepealt objekte, mille nimesid on lihtne kohanimeks pidada: teed-tänavad-väljakud, pargid jm haljasalad, tiigid, majad, ühissõidukipeatused. Nende nimed on enamasti tüüpilise kohanime struktuuriga, milles eristuvad nimetuum ja liigisõna: Merivälja tee, Roheline tänav, Vabaduse väljak, Tammsaare park, Uue Maailma haljak, Luigetiik, Urla maja, Estonia peatus. ${ }^{4}$ Peatusenimed, tõsi, on natuke erandlikud, sest nimestikes ja siltidel on tavaks viidata peatusele nime andnud objektile endale, sh tänavale (Betooni põik, Bussijaam, hotell Tallinn, Lasnamägi), ja liigisõna peatus lisatakse tekstis kasutamisel (Betooni põigu peatus, Bussijaama peatus, hotelli Tallinn peatus või hotell Tallinna peatus, Lasnamäe peatus).

Ent kas kohanimed on ka järgmistel objektidel: restoranid, kohvikud, baarid, kauplused, kaubanduskeskused, asutused, koolid, lasteaiad, haiglad, apteegid, tehased, pangad, organisatsioonid? Siin saab tugineda 2012.-2013. aastal Tallinnas tehtud välitöödele, mille sisuks oli eeskätt artefaktinimede kihi uuendamine KNABis.

Eesti Keele Instituudi kohanimeandmebaasis (KNAB) oli 1980. aastate lõpu seisuga esindatud ka väike hulk artefaktinimesid, eeskätt Tallinnast. Näiteks Tallinnast oli sellal kohanimeandmebaasis 24 restorani, 36 kohvikut, 14 hotelli ja 11 kino. Tollane nimevalik oli piiratud ja mingis mõttes Nõukogude ajastule tüüpiline (restoranid Euroopa, Gloria, Kalinka, Nord, Nõmme, Pirita, Pärnu, Szolnok, Vana Toomas, kohvikud Gnoom, Harju, Moskva, Narva, Olümpia, Schwerin, hotellid Aeroflot, Balti, Briis, Neptun, Ookean, Palace, Sport, kinod Eha, Koit, Kosmos, Oktoober, Pioneer, Rahu, Sõprus, Võit). Nimed olid lisaks kauplustel (ABC-3, Aed, Agro, Aiandus, Albatross) ning KNAB sisaldas ka asutuste (Tallinna Aiandussovhoos, Eesti Ajaloomuuseum, TLÜ Akadeemiline Raamatukogu), tehaste-vabrikute (Ilmarine, Tarbeklaas, Teras) jms nimesid.

Taani ja Skandinaavia linnakohanimesid käsitleb nt Jørgensen 2002, ent temagi ei püüa neid eriti piiritleda. Vt ka Ainiala 2004 ja 2005.

4 Näited selles jaotises pärinevad Eesti Keele Instituudi kohanimeandmebaasist KNAB. Osa nimesid võib nüüdseks olla muutunud. 
Seda kohanimede kihti uuendades oli vaja kõigepealt saada selgust, mida neist nimedest saaks üldse kohanimeks lugeda. Ärinimesid äriseadustiku $\S 7$ mõttes ei saa pidada alati kohanimeks, sest ärinimi kui juriidilise isiku nimi ei tarvitse kokku langeda ettevõtte nimega, mille all avalikkuse jaoks tegutsetakse - nt restorani Olde Hansa peab Starmaker OÜ, pubi Hell Hunt aga Hunt Kriimsilm OÜ. Starmaker OÜ ega Hunt Kriimsilm OÜ ei talitle kindlasti kohanimedena.

Lähteks võeti määratlus, et kohanimed linnas on kohtadel (objektidel), mida kasutatakse orienteerumiseks ehk kohtade leidmiseks. Teisisõnu, kui mingi objekti nime kasutatakse asukoha kirjeldamiseks, on tegu kohanimega. Praktikas ei ole muidugi alati võimalik seda üheselt määrata, seepärast tulevad arvesse ka sekundaarsed tunnused, nt kas mingi objekt on sildiga tähistatud või mitte.

Tänapäeva artefaktinimesid linnas iseloomustab äärmine mitmekesisus ja dünaamilisus: objektid tekivad, kolivad, vahetavad nime ja kaovad suure sagedusega. Näiteks Tallinnas Vabaduse väljak 10 asuv kohvik, algse nimega Kultas (1937), on hiljem kandnud nimesid Moskva (al 1951), uuesti Kultas (1990. aastate algupoolel), Metropol (19962000), Taevase Rahu Väljak (u 2000), seejärel Kultus (2009, varem ka kohvik Kuldtass), uuesti Moskva (2013) ja lõpuks Wabadus (al hiljemalt 2015) $)^{5}$, selle artikli kirjutamise ajal (2020. aasta veebruar) ootab kohvik uut omanikku ja ilmselt ka uut nime. Sageli on artefaktinimed linnas võõrkeelsed (näiteks toitlustusasutused Bocca, Brewery, Café Mademoiselle, Clayhills, Controvento, Depeche Mode, segakeelne Toit's City, hotellid Centennial, Center, Economy, Imperial, L'Ermitage, Old Town Maestro's) ja struktuurilt keerulisemad (pubi Seiklusjutte Maalt ja Merelt, vinoteek Kolme Näoga Mees, grammatikareegleid eirav Leib Resto \& Aed).

KNABis on 2020. aasta veebruari seisuga nimega artefakte järgmiselt: 11453 teed, tänavat ja väljakut, 566 parki jm avalikku kohta, 189 mitmesugust asutust (riigi ja kohaliku omavalitsuse asutused, korravalve- ja sõjaväeasutused, kohtud ja diplomaatilised esindused), 156 kultuuri- ja teadusasutust (sh muuseumid, raamatukogud, kinod, teatrid), 380 haridus- ja kasvatusasutust (sh koolid, lasteaiad), 121 meditsiiniasutust (sh haiglad, apteegid), 291 kauplust

Aastaarvud on orienteerivad ja näitavad eeskätt, millal nimi kehtis, täpsem kronoloogia puudub. Reast võib ka mõni nimi puududa, mille kohta kindlamaid andmeid pole. 
jm äri, 325 toitlustusasutust (restoranid jms), 127 hotelli, 232 äriühingut (sh tehased, pangad), 45 organisatsiooni. Peale teede-tänavate ning parkide on ülejäänud artefaktid valdavalt Tallinnast.

Kui lühidalt iseloomustada silmapaistvamaid muutusi artefaktide nimedes 1980. aastatest tänini, siis võib Tallinna näitel esile tuua järgmist.

Kui varasemal ajal oli majanimesid suhteliselt üksikuid ja needki pigem sõjaeelsest ajast (Burmanni villa, Urla maja), siis eriti 2000. aastatest alates on kinnisvaraarenduse eestvedamisel nende hulk märkimisväärselt kasvanud. Valik majanimesid: Admirali maja, Art Depoo, Karsti Kodu, Kindlustuse maja, Lootsi maja, Mäevärava maja, Nautilus, Osten Tor, Põhjatähe elamu, Reederi residents, Risti residents, Šveitsi maja. Osa neist nimedest oli aktiivsemas kasutuses eeskätt majade valmimise ajal, kui oli vaja kinnisvara reklaamida, hiljem pole neid näha olnud (nt Mäevärava maja aadressil Narva mnt 128).

Kui varem olid koolid ja lasteaiad tähistatud numbritega, siis alates 1980. aastate lõpust on need saanud endale nimed. Koolid kannavad nimesid sageli asumite järgi, kus nad paiknevad (Haabersti vene gümnaasium, Karjamaa gümnaasium, Kristiine gümnaasium, Lasnamäe gümnaasium), ent on ka oma nimega koole (Arte gümnaasium, Gustav Adolfi gümnaasium, Inglise kolledž, Reaalkool), numbrilisi on üksikuid (Tallinna 21. kool, Tallinna 32. keskkool). Lasteaedade nimed on mitmekesisemad, neis on rohkem fantaasiat: Aiake, Kalli-kalli, Kiikhobu, Lõvimeri, Memme Musi, Mesimummu, Midrimaailm, Mikumanni, Muumipere, Mürakaru, Naba, Naeratus, Pallipõnn, Päikesejänku, Päkapikk, Rõõmupesa, Sinilind.

Kauplusenimed näivad aga olevat läbi teinud taandarengu. Kauplusi nimetatakse tänapäevalgi, ent valdavalt on tegu kauplusekettide (nt Maxima, Rimi, Selver) nimedega, mida täiendatakse praktikas täpsustavate asukohaviidetega (Torupilli Selver), samuti pannakse nimesid kaubanduskeskustele (Arsenal). Väikestele üksikkauplustele pandud uusi nimesid on vähevõitu ja needki ei tundu eriti prominentsed (Bensport, Cristall, Elite Style, Glenfield, Infur). Võrdluseks: 1980. aastatel paiknesid ainuüksi Viru tänaval järgmised nimega kauplused: Aroom, Baltika (varem Riietur), Eesti King, Elegants (al 1990 Tik-Tak), Heli, Krista, Laura (varem Sipsik), Mare, Mart, Progress, Siluett, Soliid, Virge, Viruvärava raamatukauplus (varem Sõprus). 
Üks võimalus selleks, et kindlaks teha, kas tegu on kohanimega, on vaadelda objektide kohta kasutatavaid slänginimetusi. Kui kohanime kriteeriumiks on eeskätt huvi tähistada ja eristada mingit kohta maastikus teisest, siis slängiväljend näitab selgesti niisuguse huvi olemasolu.

\section{Artefakte tähistavaid slängiväljendeid}

Siinses peatükis on vaadeldud mõningaid artefakte, mida rahvasuu on tähistanud slängiväljendiga. Slängil on eri ajaperioodidel ning eri lingvistide käsitlustes vähem või rohkem erinev tähendussisu' ${ }^{6}$. Slängile on iseloomulik eelkõige eripärane või omalaadne leksika. Slängiväljendid kujunevad ja arenevad elavas keeles toimivate loomulike keeleliste protsesside tagajärjel, näiteks sõnade tähenduse teisenemine: tähenduse laienemine või muutumine mingi analoogia põhjal, pärisnimede üldistamine, uute sõnade loomine derivatsiooni teel jne (Tender 1994: 346 jj). Artefakte tähistavad slänginimedki luuakse eespool nimetatud moodusel.

Üks võimalus selleks on sufiksite kasutamine, nt -kas: Karjakas 'õllerestoran Karja kelder', Vabakas 'Vabaduse väljak või Vabaduse puiestee'; -s: Olümps 'hotell Olümpia', Kaups '(Tallinna) kaubamaja'.

Teine võimalus on sõnade lühendamine abstsisiooni ehk raie teel. See on keeleline nähtus, kus pikana tunduvat aluskeelendit lühendatakse. Tulemuseks on uus, lühike tüvi, nt Konss 'konservatoorium' ja Pegass 'kohvik Pegasus'.

Slängiväljendeid luuakse mh keelemängu elementidega, sh tähemängu ehk logogriifiga, kus mingi hääliku lisamisega, ärajätmisega, ümbertõstmisega ja tähenduse ümbermõtestamisega saab sõnu ja kõnet huvitavamaks või naljatlevamaks muuta. Sel moel tekib uudsusefekt, nt Ko-Ko-Ko kohvik (Kolme Koopa kohvik Tartus) > koobas ja koolnud koera kohvik (Palmeos 1935: 507).

Slängis kasutatakse üsna tihti fraasikujulisi nimesid, millele on iseloomulik variantide rohkus ning kirjalikul fikseerimisel teatav ortograafiline ebakindlus (millal ja kuidas kasutada suurt algustähte), nt Balti jaama juures olnud monumendi kohta kasutati väljendeid Moskva rongile

6 Slängi mõiste ning funktsioonide piiritlemise kohta vt põhjalikumalt Tender 1994: 293299 või Ilm ja Tender 2003: 12-17. 
vastu $\sim$ Rongile vastu; Rongile ruttajad või ka Monument mässule ülestõusule, kuhu kõik osalejad on ära mahtunud jt (Tender 2019).

Artefakte tähistavate slängiväljendite puhul ei ole veel võimalik tugineda KNABi-laadsele andmebaasile, seetõttu on siinses artiklis allikana kasutatud eri ajaperioodil valminud uurimusi: seminari-, kursuse-, diplomi-, bakalaureuse- ja magistritöid; publitseeritud artikleid; internetis leiduvat teavet jms. Nagu eespool nimetatud, on vaatlusest kõrvale jäetud linnade ja linnaosade slänginimed. ${ }^{7}$

Alljärgnevalt on artefakte tähistavaid slängiväljendeid liigitatud objektide järgi (see näitab, milliste artefaktide kohta on tekkinud ja tekib slängiväljendeid): ehitised ja neis paiknevad asutused, ettevõtted (sh kinnipidamiskohad, õppeasutused; söögi- ja joogikohad); monumendid, skulptuurid; sillad, viaduktid, trepid jms.

\subsection{Ehitised ja neis paiknevad asutused ning ettevõtted}

1928. aastal kasutasid Tallinna Tütarlaste Kommertsgümnaasiumi õpilased eri koolidele viidates väljendeid kontstantstoorium 'konservatoorium'; kördiklubi 'naiskutsekool'; eestika 'Eesti tütarlaste gümnaasium (Tartus)' (Allik 1928: 9-10).

1980. aastate Tallinna õpilasslängis kasutati pealinna paari kooli kohta järgmisi väljendeid: aadli pansionaat, ka punase aadli pansionaat '(endine) Tallinna 7. keskkool, nüüdne Tallinna inglise kolledž, mis tegutses nõukogude ajal praeguse prantsuse lütseumi hoones', selles õppis toonase nõukogude nomenklatuuri esindajate lapsi; aadlineitsite pansion plikade kool'(endine) Tallinna 20. keskkool, nüüdne Tallinna ühisgümnaasium, kuna seal oli ka tütarlasteklasse' (Tender 1983: 57).

Tallinna mõningaid söögi- ja joogikohti on 1970.-80. aastatel nimetatud järgmiselt: Balta kuulipilduja 'õllepaviljon Balti jaama läheduses'; Bermuda kolmnurk 'õllepaviljon Hiiul'; Karjakas 'õllerestoran Karja Kelder Tallinnas'; Pegass 'kohvik Pegasus'; Roheline Konn 'rohelist värvi puidust kohvik Kadriorg'; Tatikas 'Harju tänava jäätisekohvik (praeguse uisuväljaku kohal)'; Varblane 'Harjumäe vabaõhukohvik'; Viru lakk 'kunagine söökla Viru' (Roosileht, Laulik 1979: 51); Känd 'restoran Kännu kukk Tallinnas Mustamäel'; Külmutuskapp, Olümps

Tallinna ja selle linnaosade mõningaid nimetusi vt Loog 1991: 37-38; Tender 1994: 351. 
'hotell Olümpia, rajati 1980. aasta Tallinna olümpiaregati eel'; Rebaseurg 'restoran Nord Tallinna vanalinnas' (Tender 1983: 57).

Tartu üliõpilaseluga, nt õppehoonete ja ühiselamutega seotud väljendeid, mis on fikseeritud 1960. aastate teisel poolel: Laibakum 'anatoomikum', Marksumaja 'marksismimaja', Seminarka 'seminari raamatukogu', Tuubikum 'õpperaamatukogu', Pälsoni pansion 'Pälsoni tänava internaat', Tiigi lomp 'Tiigi tänava internaat', Jaama hotell 'EPA internaat Jaama tänaval' (Poolma 1966: 2-4).

1985. aastal valmis Tallinna südalinnas Sakala poliithariduskeskus (arhitekt Raine Karp), praegune Solaris, mida tolleaegse Eestimaa Kommunistliku Partei Keskkomitee esimese sekretäri Karl Vaino ning ehitise arhitektuurielementide (uusgooti stiilis torn) järgi hakati kutsuma Karla katedraal $\sim$ Karl Vaino katedraal $\sim$ Vaino katedraal $\sim$ Püha Vaino katedraal Pühavaino kirik, samuti Leniniitlaste klooster (Tender 2019).

2005. aastal avatud Tartu uus kaubamaja on saanud rahva seas hüüdnime Tallinna ülikool. Hoonet kritiseeris ajalehes kunstiajaloolane Enriko Talvistu, kes kirjeldas rajatist sõnadega „tehniliste ruumide kuubikud mingite sammastega kasti peal“ ning lisas järgmist: „õigus on nendel, kes sambaid üle lugedes saavad aru, et see on „Tallinna Ülikool“ Tartus. "8 (Tender 2019).

Tartus Kitsal tänaval asus aastail 1978-2000 betoonist Lollijala trepp (ka trepp Lolljalg). Trepiastmed olid madalad ja 60-70 cm laiused ning neid ei olnud võimalik kas ühe või siis kahe normaalpikkuses sammuga läbida, selleks tuli astuda üks normaalpikkusega samm ning seejärel lühike vahesamm, seejärel jälle üks pikk ning jällegi lühike samm. ${ }^{9}$ (Tender 2019).

\subsection{Monumendid, skulptuurid}

Tartusse Vabaduse puiesteele Emajõe äärde püstitati 1933. aastal skulptor Amandus Adamsoni Vabadussõja mälestussammas, nn Kalevipoeg, mis nõukogude võimutegelaste käsul 1950. aasta aprillis hävitati. Kuna rahvas jätkas samasse kohta lillede toomist, siis paigaldati sinna 1952. aastal Friedrich Reinhold Kreutzwaldi monument, mis püsis seal

\footnotetext{
Tartu Kaubamaja - https://et.wikipedia.org/wiki/Tartu_Kaubamaja/(vaadatud 20.02.2020).

9 Tartu linna kultuuriväärtusega asjade ja mälestiste register - https://info.raad.tartu.ee/ muinsus.nsf/ (vaadatud 20.02.2020).
} 
Kalevipoja skulptuuri taastamiseni 2003. aastal. Rahvasuu nimetas Kalevipoja skulptuuri asemel seisnud Kreutzwaldi monumenti Isa oma poja haual.

Tallinnas rahvusooper Estonia ja Draamateatri kõrval Pärnu maantee ääres paiknevat skulptor Lembit Palutederi ning arhitekt Mart Pordi 1905. aasta veriste sündmuste mälestusmärki on rahvasuu tähistanud väljenditega Ema, ära löö isa! ning Taksohääletajad või Taksopeatajad.

Tallinnas Pirita tee ääres Maarjamäe memoriaalis paikneb 1960. aastal valminud 35 meetri kõrgune Jääretke obelisk, autoriteks arhitekt Mart Port ja skulptor Lembit Tolli. Rahvasuus kannab obelisk järgmisi nimesid: Buratino haud, ka Impotendi unistus $\sim$ Impotendi unenägu $\sim$ Mart Pordi noku.

Tallinnas Vabaduse väljakul paikneb 2009. aastal avatud 23,5 meetri kõrgune klaasplokkidest Vabadussõja võidusammas. Kuna see rajati Jaak Aaviksoo kaitseministriks olemise ajal, siis rahvasuus on see Aaviksoo rist ning Suur-Jaak. Peale selle on sammast kutsutud ka nimega Ivan Orava haud. ${ }^{10}$

Maailmakuulsa semiootiku Juri (Jüri) Lotmani auks rajati 2007. aasta sügisel Tartu Ülikooli raamatukogu lähedusse metalltorudest valmistatud mälestusmärk-purskkaev. Viiest 15-meetrisest terastorust skulptuuri idee põhineb Juri Lotmani autošaržil. Rahvasuus kutsutakse seda purskkaevu Toru-Jüri (alapeatüki näited: Tender 2019).

\subsection{Sillad, viaduktid}

Tallinna Pärnu maantee viadukt, mille alt kulgeb raudtee, oli rahva seas nõukogudeaegses kõnepruugis Hendriksoni küür, kuna viadukti valmimise ajal juhtis Tallinna linna täitevkomitee esimees Aleksander Hendrikson. Toonane viadukt oli praegusest, 1980. aastatel rekonstrueeritud uuest viaduktist lühem ja mitu meetrit kõrgem.

Tartus avati 1981. aastal Sõpruse sild, mis sai rahvasuus tollase linnajuhi (täitevkomitee esimehe) Nikolai Preimani järgi nime Preimani purre. ${ }^{11}$ Sama analoogia põhjal on Tartusse 2003. aastal rajatud Turusild (vantsild) saanud toonase linnapea järgi hüüdnimeks Ansipi purre (Tender 2019).

10 „Ivan Orav (1908-2009) astus Igaviku teele“ - https://elu.ohtuleht.ee/334568/ivanorav-1908-2009-astus-igaviku-teele/ (vaadatud 08.05.2020).

11 Sõpruse sild (Tartu) - https://et.wikipedia.org/wiki/S\%C3\%B5pruse_sild_(Tartu)/ (vaadatud 20.02.2020). 


\section{Kokkuvõtteks}

Artefaktinimed on väga kirju ja mitmekesine nimerühm - seda nii tähistatavate objektide erinäolisuse ja arvukuse poolest kui ka kasutusvaldkonniti ja piirkonniti, näidates eri pilti maal ja linnas, kirjakeeles ja slängis.

Artikli algusosas toodi esile, millisel moel on artefaktinimesid klassifitseeritud. Sedastati, et artefaktinimedeks võib liigitada kõik need inimtegevusest põhjustatud objektide nimed, mis muude kultuurnimeliikide (asustusnimed, viljelusnimed) alla ei sobitu.

Kuna artefaktinimed eri kasutussfäärides sedavõrd erinevad, vaadeldi artikli kolmes sisupeatükis artefaktinimede kasutust 1) maapiirkonnas; 2) linnapiirkonnas; 3) slängis. Kõigi nende kasutusvaldkondade puhul ilmnes selgesti, kui erilaadilised võivad olla artefaktinimed.

Maapiirkonna artefaktinimesid vaadeldi kahe kihelkonna, Jüri ja Kose kihelkonna kohanimekogude baasil. Selgus, et nimetatud artefaktid olid valdavalt mingit laadi ehitised ja rajatised (veskid, sillad, koolimajad, maanteed jne) ning kõige sagedasemad artefaktinimed olid küüninimed, kõrtsinimed, teenimed ja veskinimed. Ilmnes ka, et tihedamini esinevad artefaktinimetused langesid suuresti kokku Võrumaal esinenutega. Nimede struktuur oli valdavalt klassikaline ja järgis tavapärast eesti kohanimede malli.

Kui traditsioonilise maapiirkonna artefaktinimede liigitamine paistab olevat küllaltki selgepiiriline ja arusaadav, siis linliku keskkonnaga kaasas käivad artefaktid ja nende nimetamine muudavad pildi juba tunduvalt segasemaks, nimed on raskemini piiritletavad ja määratletavad. Esineb rohkem võõrkeelseid ja struktuurilt keerukamaid nimesid.

Slängis kasutatavaid artefaktinimesid iseloomustab suur varieeruvus ja loomingulisus, mh eristuvad need tavalistest kohanimedest selle poolest, et artefaktidele võidakse viidata fraasikujuliste nimedega.

Artefaktinimesid uurides tõusevad teravamalt esile nime ja mittenime eristamise probleemid, nt kas fraase saab ülepea lugeda pärisnimedeks. Äärmist mitmekesisust arvestades vajaksid ilmselt mitmekesistamist ka artefaktinimede uurimiseks kasutatavad meetodid. 


\title{
Aadressid:
}

Tiina Laansalu

Eesti Keele Instituut

Roosikrantsi 6

10119 Tallinn

E-post: tiina.laansalu@eki.ee

Peeter Päll

Eesti Keele Instituut

Roosikrantsi 6

10119 Tallinn

E-post: peeter.pall@eki.ee

\section{Tõnu Tender}

Eesti Keele Instituut

Roosikrantsi 6

10119 Tallinn

E-post: tonu.tender@eki.ee

\begin{abstract}
Allikad
$\mathrm{KN}=$ Eesti Keele Instituudi murdearhiivi kohanimekartoteek.

$\mathrm{KNAB}=$ Eesti Keele Instituudi kohanimeandmebaas. Saadaval Internetis

$<$ http://www.eki.ee/knab/knab.htm>. Vaadatud 09.10.2019.

$\mathrm{KNV}=$ Eesti Keele Instituudi murdearhiivi kohanimekartoteegi veebiversioon. Saadaval Internetis $<$ http://heli.eki.ee/kohanimed/>. Vaadatud 18.09.2019.
\end{abstract}

\section{Kirjandus}

Ainiala, Terhi (2002) „Place names changes and losses“. Rmt. Eva Brylla, Maria Ohlsson ja Mats Wahlberg, toim. Proceedings of the 21st international congress of onomastic sciences Uppsala 19-24 August 2002, 5, 297-304. Uppsala: Institutet för språk och folkminnen.

Ainiala, Terhi (2004) „Kaupungin paikat ja nimet: Tornion Seurasaaren nimistö“. Virittäjä 108, 35-55.

Ainiala, Terhi (2005) „Tutkimuskohteena kaupunkinimistö“. Rmt. Terhi Ainiala, toim. Kaupungin nimet. Kymmenen kirjoitusta kaupunkinimistöstä. (Kotimaisten kielten tutkimuskeskuksen julkaisuja, 134.) Vantaa: Suomalaisen Kirjallisuuden Seura. 
Ainiala, Terhi, Minna Saarelma ja Paula Sjöblom (2012) Names in focus: an introduction to Finnish onomastics. Helsinki: Finnish Literature Society. https://doi. org/10.21435/sflin. 17

Allik, C. (1928) „Tallinna keskkooliõpilaste erikeelest“. Eesti Keel 1-2, 3-11.

EKS 2019 = Langemets, Margit, Mai Tiits, Udo Uibo, Tiia Valdre ja Piret Voll, toim (2019) Eesti keele sõnaraamat. Eesti Keele Instituut. Sõnaveeb 2019. Saadaval Internetis $<$ https://sonaveeb.ee/>. Vaadatud 18.09.2019.

Faster, Mariko (2018) „Etunimed ja teised Hargla hüdronüümid“. Emakeele Seltsi aastaraamat, 31-76. https://doi.org/10.3176/esa63.02

Faster, Mariko (2020) Hargla kihelkonna vetenimed Eesti-Läti piirialal. (Dissertationes philologiae estonicae Universitatis Tartuensis, 47.) Tartu: Tartu Ülikooli kirjastus.

Ilm, Uno ja Tõnu Tender (2003) Trellide ja luku taga. Tartu: Atlex.

Jørgensen, Bent (2002) „Urban toponymy in Denmark and Scandinavia“. Onoma 37, 165-179. https://doi.org/10.2143/ONO.37.0.519189

Kallasmaa, Marja (2005) „Eesti kohanimede liigitamisest“. Keel ja Kirjandus 2, 136-140.

Kiviniemi, Eero (1990) Perustietoa paikannimistä. (Suomi, 148.) Helsinki: Suomalaisen Kirjallisuuden Seura.

Laansalu, Tiina (2020) Kesk-Harjumaa kohanimede kujunemine ja nimesiire. (Dissertationes philologiae estonicae Universitatis Tartuensis, 46.) Tartu: Tartu Ülikooli kirjastus.

Langemets, Margit, Mai Tiits, Tiia Valdre, Leidi Veskis, Ülle Viks ja Piret Voll, toim. (2009) Eesti keele seletav sõnaraamat. Tallinn: Eesti Keele Sihtasutus.

Loog, Mai (1991) Esimene eesti slängi sõnaraamat. Tallinn: Oma kulu ja kirjadega.

Palmeos, Paula (1935) „Tartu üliõpilaste erikeelest“. Üliõpilasleht 12-15. XI, Korp! Filiae Patriae erinumber 19. aastakäik, 506-514.

Poolma, Ellen (1966) Üliõpilaste kõnekeeles esinev argoosõnavara. Seminaritöö, eesti filoloogia II kursus. Tartu: Tartu Riiklik Ülikool.

Päll, Peeter (2018) „Eesti kohanimed“ Karl Pajusalu, Tiit Hennoste, Ellen Niit, Peeter Päll ja Jüri Viikberg Eesti murded ja kohanimed. 3., kohendatud ja täiendatud trükk. Tartu. Saadaval Internetis <http://www.emakeeleselts.ee/digiraamatud/Eestimurded-ja-kohanimed_kolmas-trykk_2018.pdf $>$. Vaadatud 19.09.2019.

Roosileht, Allan ja Aimar Laulik (1979) Keskkooliõpilaste kõnepruuk. [Tallinna Pedagoogilise Instituudi diplomitöö, mis on esitatud ESi sõnavara kogumise võistlusele märgusõnaga Jämm 79] Käsikiri (hoiul Eesti Keele Instituudis). Tallinn.

Saar, Evar (2008) Võrumaa kohanimede analüüs enamlevinud nimeosade põhjal ja traditsioonilise kogukonna nimesüsteem. (Dissertationes philologiae estonicae Universitatis Tartuensis, 22.) Tartu: Tartu Ülikooli kirjastus.

Simm, Jaak (1976) „Nimeteaduse põhimõisteid“ Mart Mäger, koost. Keel, mida me uurime, 137-140. Tallinn: Valgus.

Tender, Tõnu (1983) Tallinna 20. Keskkooli õpilasslängi (1982-1983). Käsikiri. Tallinn.

Tender, Tõnu (1994) „Eesti släng: olemus ja uurimislugu“. Keel ja Kirjandus 5, 291299 ja $6,346-355$.

Tender, Tõnu (2019) „Etüüd slängi näost: kriimus koon või klants sihverplaat?“ Ettekanne 52. J. V. Veski päeval „Eesti keele mitu nägu“ 27.06.2019 Tartu Ülikoolis. 
Vääri, Eduard, Richard Kleis, Johannes Silvet, Tiina Paet ja Tuuli Rehemaa (2012) Võõrsõnade leksikon. 8., põhjalikult ümber töötatud trükk. Eesti Keele Instituut, Kirjastus Valgus. Saadaval Internetis <https://www.eki.ee/dict/vsl/>. Vaadatud 18.09.2019.

ÕS 2018 = Raadik, Maire, toim (2018) Eesti õigekeelsussõnaraamat ÕS 2018. EKSA: Tallinn. Saadaval Internetis $<$ https://www.eki.ee/dict/qs/>. Vaadatud 18.09.2019.

\begin{abstract}
Tiina Laansalu, Peeter Päll, and Tõnu Tender: An attempt to describe artefact names. Artefact names have been traditionally classified as a subtype of cultural names designating names of man-made facilities. The number of human-constructed objects is growing rapidly and they are very diverse, especially in the urban environment, therefore the classical description of artefact names needs updating and elaborating. The article looks into artefact names in three domains: the rural environment, the urban environment and slang expressions. Examples of rural artefact names have been taken from the Jüri and Kose parishes in Harjumaa, urban names are based on the data from Tallinn of the Place Names Database (KNAB) of the Institute of the Estonian Language, slang names are taken from various sources covering mainly Tallinn and Tartu.
\end{abstract}

Keywords: onomastics, place names, artefact names, slang names, linguistic landscape, Estonian 